\title{
An experimental approach to a multiple saturation point of a "direct ascent" petit-spot basalt
}

TAKU YUtANi ${ }^{1 *}$, Pierre CONDAMINE ${ }^{2}$, NAOTO HIRANO $^{1}$, CATHERINE MCCAMMON ${ }^{3}$, DANIEL FROST ${ }^{3}$

${ }^{1}$ Tohoku University, Japan t.yutani@dc.tohoku.ac.jp

${ }^{2}$ University of Lorraine, France

${ }^{3}$ University of Bayreuth, Germany

The asthenosphere, a ductile layer of the upper mantle, facilitates the horizontal movement of plates. Although seeking out geophysical and geochemical characteristics of the asthenosphere is essential for unravelling the origin of plate tectonics, the physical conditions that distinguish the lithosphere and the asthenosphere are under debate. Several studies have proposed the presence of partial melt in the asthenosphere. However, rheological properties of mantle minerals change due to the presence of water with even small amounts of partial melt.

Petit-spot, a new type of monogenetic volcano discovered at the beginning of the $21^{\text {st }}$ century, mainly occurs as a submarine knoll. According to geological and petrological observations of alkaline basalts from petit-spot volcanoes, several studies have proposed the possibility that the petitspot melt originates in melt ponds at the lithosphereasthenosphere boundary. Moreover, newly discovered samples, so-called the "direct ascent" melts from the northwest Pacific Ocean, show more primitive characteristics than previously reported ones, which suggests that they preserve some information on the source regions as well.

Here, we show results of high-pressure experiments to seek out multiple saturation points of the "direct ascent" petitspot lavas in research supported by a JSPS Japanese-German Graduate Externship. Multiple saturation points reveal the P$\mathrm{T}$ conditions and lithologies where primary melt last equilibrated. The results confirm that the "direct ascent" petitspot magma came from the asthenosphere. 